Bull. Egypt. Soc. Physiol. Sci. Vol. (41) Issue (3), 399-409

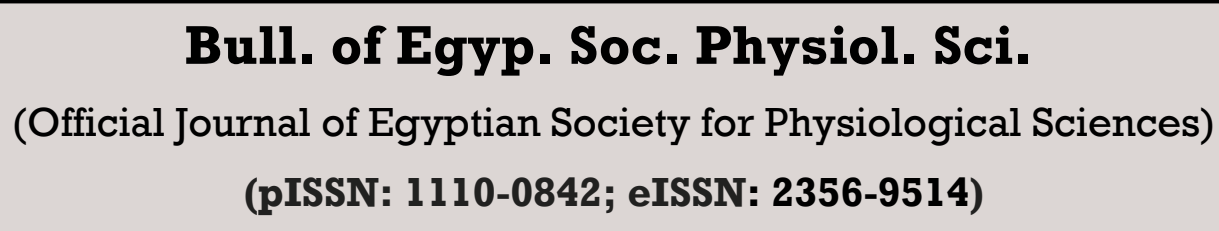

Bull. of Egyp. Soc. Physiol. Sci.

(pISSN: 1110-0842; eISSN: 2356-9514)

\title{
Role of Brain Derived Neurotrophic Factor and Swimming Exercise in Cardiac Autonomic Neuropathy in Type 2 Diabetes Rat Model
}

\author{
Mai Adawi*, Mona F Mansour *, Mohamed Abdo*, Magda I Mohamed* \\ *Physiology Department, Faculty of Medicine, Suez Canal University, Ismailia, Egypt
}

Submit Date: August 29, 2020

Accept Date: Jan 4, 2021

Available Online: Feb 1, 2021

Keywords

Cardiac autonomic

neuropathy

DM I

BDNF

Swimming exercise

\section{Abstract}

CAN is one of the major chronic complications of DMII.-Clinical investigations have revealed that uncontrolled DM II is frequently associated with lower levels of BDNF. This study assessed whether diminished BDNF level is the reason of CAN caused by DM II and if swimming aerobic exercise can increase BDNF level to ameliorate that CAN in rats. Sixty rats were divided into six groups. Group I; Normal $(N)$, Group 2; BDNF blocker, Group 3; DM II, Group 4; DM II + BDNF, Group 5; DM II + Swimming exercise and Group 6; DM II + Swimming exercise + BDNF blocker. Induction of DM II was done by intraperitoneal injection of $180 \mathrm{mg} / \mathrm{kg}$ of Nicotinamide 30 minutes before injection of $50 \mathrm{mg} / \mathrm{kg}$ Streptozocin. Swimming exercise began with a 1-week adaptation with gradual increase of swimming duration until reaching $1 \mathrm{~h}$ swimming/day at the end of the 1st week. Then, a 7-weeks training program with 5 days/week swimming was followed. The duration of the experiment was 8 weeks during which the following parameters were measured: body weight, random blood glucose "RBG" level, plasma insulin level, heart rate "HR", systolic blood pressure "SBP", heart rate variability "HRV", baroreflex sensitivity "BRS", vascular sympathetic tone "VST" and plasma BDNF. Results revealed that BDNF significantly improved RBG level, HRV, VMT and BRS. Swimming exercise significantly increases plasma BDNF level and also improved CAN. Conclusively, BDNF can be used as a treatment regimen for CAN. Also swimming exercise has great therapeutic effect on CAN maybe by producing BDNF.

Corresponding author: Mona Farouk Mansour, Department of Physiology, Faculty of Medicine, Suez Canal University, Egypt. Email: mona_mansour@med.suez.edu.eg; Tel.: +201271022990. 


\section{INTRODUCTION}

Cardiac Autonomic Neuropathy (CAN) is one of the major chronic complications of Type 2 DM (DM II). CAN devastates the autonomic nerve fibers, which innervate the blood vessels and heart leading to abnormalities in autonomic control of vascular dynamics and heart rate (1). It was accounted for that CAN increases the mortality of diabetic patients. Clinically, CAN is usually estimated by baroreflex sensitivity (BRS) and heart rate variability (HRV) tests to assess sympathetic and parasympathetic systems performance (2). Brain Derived Neurotrophic Factor (BDNF) is one of the neurotrophin family that involves Nerve growth factor, neurotrophin-3, neurotrphin-6, neurotrophic-4/5. BDNF is existing in several tissues as the mammalian brain, muscles, liver and adipose tissue (3). By activating its major tropomyosin receptor kinase B (trkb), BDNF performs an essential role in different aspects of developmental and grown-up brain neuroplasticity, involving generation, differentiation, endurance of neurons, neurogenesis, synaptic plasticity, and cognition (4). Clinical investigations have revealed that impairment of glucose metabolism found in DM II is frequently associated with lower levels of BDNF (5). Exercise has been shown to be a successful method for enhancing deficiencies in HRV and BRS in both experimental and clinical type $1 \mathrm{DM}$ (6). Acute and intense physical exercise increase BDNF production in some species including humans. Moreover, increased BDNF levels were associated with enhanced exercise performance (7), while the beneficial impact of exercise on cognition and integrated functions was restrained when blocking BDNF activity in the hippocampus (8). That's why this study aimed to assess whether diminished BDNF level is the reason of CAN caused by DM II and if swimming aerobic exercise can increase BDNF level to ameliorate that CAN in rats.

\section{Materials and Methods}

\subsection{Experimental Animals}

Sixty adult male Albino rats, 2-month old weighed 200-250gm were included in the study (purchased from the Ophthalmology Research Institute, Giza, Egypt). Current study was approved by the Research Ethics Committee, Faculty of Medicine, Suez Canal University (protocol number 3080). Animals had free access to food and water and were housed in individual cages with appropriate 12-hours light-dark cycle. They were left one week for acclimatization before the start of the study. The study was carried out in in the medical Physiology Department Laboratory, Faculty of Medicine, Suez Canal University.

\subsection{Study groups}

Rats were randomly divided into six equal groups ( $\mathrm{n}=10$ rats/group): Group I (Normal group): included normal rats that did not receive any injury or treatment. Group II (BDNF blocker group): included normal rats who received BDNF blocker injection for the first two weeks of the study. Group III (DM II group): included rats exposed to DM II induction with no treatment. Group IV (DM II + BDNF group): included rats with induced DM II, then received BDNF injection for four weeks. Group V (DM II + Swimming exercise group): included rats with induced DM II, then exposed to swimming exercise program for 8 weeks. Group VI (DM II + Swimming exercise + BDNF blocker group): included rats with 
induced DM II, then exposed to swimming exercise for 8 weeks and received BDNF blocker injection at both $7^{\text {th }}$ and $8^{\text {th }}$ weeks of the study.

\subsection{Induction of DM II}

DM II was induced by intraperitoneal injection of $180 \mathrm{mg} / \mathrm{kg}$ of Nicotinamide (NA) ( Serva Electrophores, Germany (Catalog No: 3031201) dissolved in saline, 30 minute before injection of $50 \mathrm{mg} / \mathrm{kg}$ of Streptozocin (STZ) (Bio-techne, Europe (Catalog No: 1621) dissolved in 0.1 citrate buffer ( $\mathrm{pH} 4.5)$ by intravenous route via rat tail vein. The rats were given $5 \%$ glucose solution as drinking water in the first day after STZ induction to prevent hypoglycemia (9).

\subsection{Injection of BDNF and BDNF blocker}

Tail vein injection of BDNF (human recombinant BDNF, Sigma-Aldrich, USA (Catalog No: B3795) in group (IV) was done after confirming diabetes with a dose of ( 0.4 micro gram $/ \mathrm{kg} /$ day $)$ every day for 4 weeks(10). Intraperitoneal injection of BDNF blocker (TrkB "tropomyosin receptor kinase or tyrosine receptor kinase B" inhibitor (K252a; Biotechne, Europe (Catalog No: 1683) was done in group (II \& VI) with a dose of $50 \mathrm{mg} / \mathrm{kg}$ of body weight daily for 2 weeks (11).

\subsection{Swimming exercise}

After induction of diabetes, groups (V \& VI) were exposed to a swimming exercise program for 8 weeks as follows: Exercise began with a 1-week adaptation period to prevent animal stress during which, the swimming duration increased daily as tolerated by the rat until reaching $1 \mathrm{~h}$ swimming/day at the end of the 1st week. After that, a 7-weeks training program with 5 days/week swimming was followed during which, the duration of swimming activity was kept constant while intensity increased every week in this way: each rat was loaded with increasing weight (metal ring) to increase resistance ( $1 \%$ of the body weight in the second week, increasing to $5 \%$ of the body weight in the 6th and 7th week). Weights were tied to a rope and wrapped up around the rat trunk to make it capable of free swimming despite the weight. Swimming exercise was performed in a large glass container divided into three equal chambers to allow the researcher to observe the rats during swimming. Each chamber was filled with warm water $\left(35 \pm 1{ }^{\circ} \mathrm{C}\right)$ to prevent hypothermia (12).

\subsection{Measurements and follow-up}

\subsubsection{To confirm the occurrence of DM II:}

Body weight (weekly), Random blood glucose level (weekly) \& Fasting Plasma insulin level (at zero and $8^{\text {th }}$ week) using ELISA kit (RayBio, USA, Catalog No: ELR-Insulin).

\subsubsection{Assessment of CAN as a complication of DM} II:

The following tests were done at 0,4 and 8 weeks of the study (12). using BIOPAC MP150 Data Acquisition System (BIOPAC Systems, Inc, California. USA) according to the manual guidelines. Measurement of blood pressure only was done without anesthesia then the rats were anesthetized using Thiopental sodium $(60 \mathrm{mg} / \mathrm{kg})$ by intraperitoneal injection (Thiopental Sodium $500 \mathrm{mg}$, Egyptian Int. Pharmaceutical Industries Co. (E.I.P.I.CO.) - Egypt) for measurement of the remaining tests (13).

\section{Systolic blood pressure (SBP)}

2. Basal Heart Rate (BHR)

3. Vascular Sympathetic Tone (VST): The vascular sympathetic tone was used to measure the sympathetic contribution to vascular resistance so that mean arterial blood pressure 
(MABP) was assessed before and after a bolus injection of the $\alpha$-adrenergic receptor blocker as follows: MABP was measured then a rapid intravenous bolus of $85 \mu \mathrm{g} / \mathrm{Kg}$ Prazosin (Sigma-Aldrich, USA, Catalog No: P7791) was injected \& the percent change in MAP was assessed (14).

4. Heart Rate Variability (HRV) (time domain (SDNN) \& frequency domain (LF, HF \& LF/HF ratio)

5. Baroreflex Sensitivity (BRS): ECG and MAP were recorded simultaneously then a rapid intravenous bolus of $12 \mu \mathrm{g} / \mathrm{kg}$ of Phenylephrine (PE) (Egyptian INT. Pharmaceutical Industries CO, Egypt, Batch No. B1508671A) was injected to the rat and the changes were recorded. After returning to the basal HR and MAP, a rapid intravenous bolus of $60 \mu \mathrm{g} / \mathrm{Kg}$ Glyceryl trinitrate (GN) (Sunny Pharmaceutical, Egypt, Batch No. 15252C) was injected to the rat and the changes were recorded as well. Responses to $\mathrm{PE}$ and GN for each rat were plotted separately and only regression lines (slopes) with correlation coefficients $(r) \geq 0.70$ and $p<0.05$ were accepted ${ }^{(15)}$.

\subsubsection{Plasma BDNF level:}

For testing the possible underlying mechanism of CAN, Plasma BDNF level were measured at the $4^{\text {th }}$ and $8^{\text {th }}$ week of the study using ELISA kit (Rat BDNF ELISA Kit, Thermo Scientific, USA (Catalog No: ERBDNF) ${ }^{(16) .}$

\subsection{Statistical analysis:}

Statistical analysis was done using SPSS (version 24.0; SPSS INC, Chicago, IL). It includes descriptive statistics and comparative analysis. Paired T-test, ANOVA and post-hoc Tukey test were used to compare groups. P-value of $\leq 0.05$ was considered as statistically significant. Graphs and charts were produced by Microsoft Excel 2019 software.

\section{Results}

\subsection{Confirmation of DM II induction}

\subsubsection{Random blood glucose level}

Using One Way ANOVA and Post-Hoc Tukey test, establishment of DM II was confirmed throughout the study by the significant elevation in RBG level in all diabetic groups $(3,4,5 \& 6)$ compared to $N$ group $(\mathrm{P}<0.05)($ Table 1, fig. 1A). All the treated groups $(\mathbf{4 , 5} \& \mathbf{6})$ showed significant improvement in RBG level compared to DM II group.

\subsubsection{Body weight}

Using one way ANOVA and Post-Hoc Tukey test, DM II group showed a significant decrease in body weight in comparison to normal group ( $\boldsymbol{P} \leq$ 0.001 at $4^{\text {th }}$ and $8^{\text {th }}$ week) (Table 1, fig. 1B). BDNF injection decreased diabetic rats body weight significantly compared to DM II group ( $\boldsymbol{P}$ $\leq 0.001$ at $4^{\text {th }}$ and $8^{\text {th }}$ week) in contrast to swimming exercise which increased diabetic rats body weight significantly in comparison to DM II group ( $P \leq 0.001$ at the $4^{\text {th }}$ and $8^{\text {th }}$ week $)$. On the other hand, BDNF blocker administration resulted in a significant increase in rats body weight in both group 2 (BDNF blocker group) $(P \leq 0.001$ at $4^{\text {th }}$ and $8^{\text {th }}$ week compared to $\mathrm{N}$ group) and group 6 (DM II + Swimming exercise + BDNF blocker group) $\left(P \leq 0.001\right.$ at the $8^{\text {th }}$ week compared to DM II group). 


\begin{tabular}{|c|c|c|c|}
\hline \multicolumn{4}{|c|}{ Table (1): RBG, and body weight of different study groups at the 4th and 8th week of the study. } \\
\hline Group & Week & Body Weight in gm & RBG in $\mathrm{mg} / \mathrm{dl}$ \\
\hline Group I & $4^{\text {th }} \mathrm{wk}$ & $243 \pm 0.99 \mathrm{gm}^{\#}$ & $117 \pm 1.53 \mathrm{mg} / \mathrm{dl} \#$ \\
\hline & $8^{\text {th }}$ wk & $287 \pm 1.02 \mathbf{g m}^{\#}$ & $115 \pm 0.47 \mathrm{mg} / \mathrm{dl} \mathrm{\#}$ \\
\hline Group II & $4^{\text {th }}$ wk & $270 \pm 0.49 \mathrm{gm}^{* \#}$ & $138 \pm 0.61 \mathrm{mg} / \mathrm{dl} * \#$ \\
\hline BDNF Blocker & $8^{\text {th }}$ wk & $295 \pm 0.80 \mathrm{gm} * \#$ & $141 \pm 0.70 \mathrm{mg} / \mathrm{dl} * \#$ \\
\hline Group III & $4^{\text {th }} \mathrm{wk}$ & $229 \pm 2.10 \mathrm{gm}^{*}$ & $232 \pm 0.73 \mathrm{mg} / \mathrm{dl} *$ \\
\hline DM II & $8^{\text {th }} \mathrm{wk}^{2}$ & $229 \pm 1.93 \mathrm{gm} *$ & $234 \pm 0.72 \mathrm{mg} / \mathrm{dl} *$ \\
\hline Group IV & $4^{\text {th }} \mathrm{wk}$ & $215 \pm 1.01 \mathrm{gm}^{* \#}$ & $197 \pm 1.02 \mathrm{mg} / \mathrm{dl} * \#$ \\
\hline DM II + BDNF & $8^{\text {th }}$ wk & $200 \pm 0.88$ gm $^{* \#}$ & $171 \pm 0.62 \mathrm{mg} / \mathrm{dl} * \#$ \\
\hline Group V & $4^{\text {th }} \mathrm{wk}$ & $237 \pm 1.3 \mathrm{gm}^{* \#}$ & $215 \pm 1.45 \mathrm{mg} / \mathrm{dl} * \#$ \\
\hline DM II + Swim. & $8^{\text {th }}$ wk & $281 \pm 1.1 \mathrm{gm}^{* \#}$ & $185 \pm 1.81 \mathrm{mg} / \mathrm{dl} * \#$ \\
\hline Group VI & $4^{\text {th }} \mathrm{wk}$ & $240 \pm 2.40 \mathrm{gm}^{\#}$ & $207 \pm 1.77 \mathrm{mg} / \mathrm{dl} * \#$ \\
\hline DM II + Swim. + BDNF Blocker & $8^{\text {th }} \mathrm{wk}$ & $295 \pm 1.07 \mathrm{gm}^{* *}$ & $204 \pm 1.81 \mathrm{mg} / \mathrm{dl} * \#$ \\
\hline
\end{tabular}

Data were obtained using One Way ANOVA and Post-Hoc Tukey test. Data are expressed as mean \pm SEM. (*) Significant $P$ value $(P \leq 0.05)$ in comparison to group $(N)$. (\#) Significant $P$ value $(P \leq 0.05)$ in comparison to group (DM II).

\subsubsection{Plasma insulin}

Plasma insulin level was measured in all groups before the start and at the end of the study (fig.1C). Using paired $\mathrm{T}$ test, Plasma insulin level didn`t change significantly in the groups during the study except on administration of BDNF blocker in groups $2 \& 6$, which caused significant increase in their insulin level.

\subsection{Assessment of CAN:}
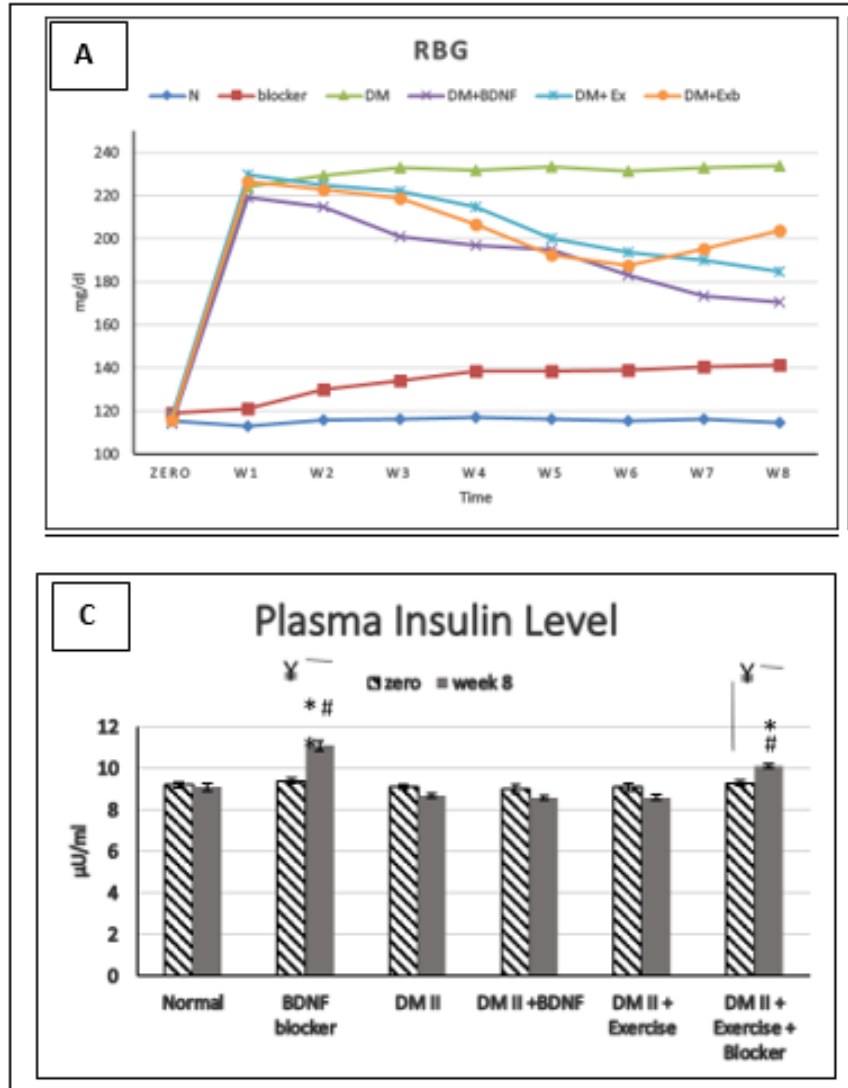

\subsubsection{Systolic blood pressure (SBP)}

Induction of DM II caused significant increase in SBP in all diabetic groups $(3,4,5 \& 6)$ compared to

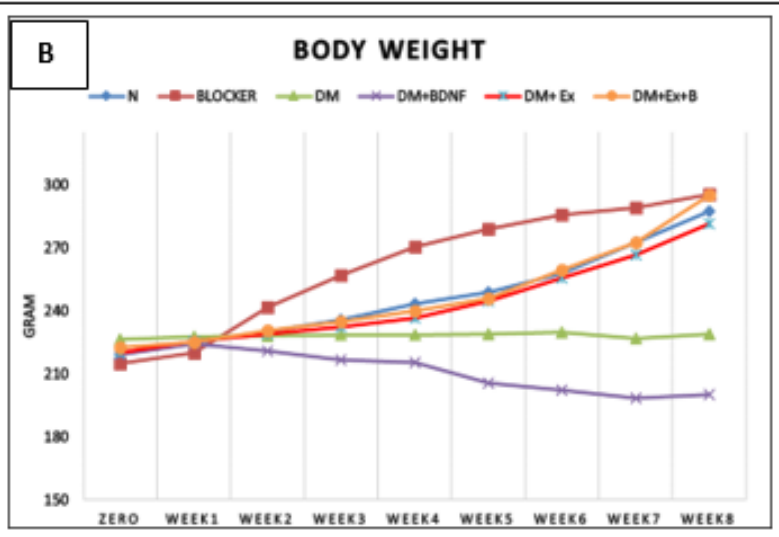

Figure (1): measurements to confirm DMIl throughout the study. A: RBG of the studied groups over the entire period of the study. Data are expressed as means. B: Body weight of the studied groups over the entire period of the study. Data are expressed as means. C: plasma insulin level in the study groups at zero and 8th week. Data were obtained using paired $\mathrm{T}$ test and One-Way ANOVA among groups. Data are expressed as mean \pm SEM. ( $¥$ ) Significant $P$ value $(P \leq 0.05)$ in comparison to zero level of the same group. $\left.{ }^{*}\right)$ Significant $P$ value $(P \leq 0.05)$ in comparison to group (N). (\#) Significant $P$ value $(P \leq 0.05)$ in comparison to group (DM II).

$\mathrm{N}$ group $(\mathrm{P} \leq 0.000)$ at the $4^{\text {th }}$ week. However, at the $8^{\text {th }}$ week, this increase of SBP in diabetic rats significantly improved in groups $5 \& 6$ compared to 
diabetic rats in untreated group $3(\mathrm{P} \leq 0.001)$ (fig.2A).

\subsubsection{Basal heart rate (BHR)}

As shown in fig.2B in $\boldsymbol{D M} \boldsymbol{I I}$ group, BHR decreased significantly in comparison to $N$ group at the $8^{\text {th }}$ week only $(\boldsymbol{P} \leq \mathbf{0 . 0 0 1})$. Administration of $\boldsymbol{B D N F}$ significantly improved the $8^{\text {th }}$ week BHR in $D M I I+B D N F$ group.

\subsubsection{Vascular sympathetic tone test (VMT)}

DM II groups showed significant increase in their $\%$ change in MAP in comparison to $\mathrm{N}$ group $(\mathrm{P} \leq$ 0.001). However, BDNF injection, swimming and even BDNF blocker injection showed significant decrease in their \% change in MAP compared to DM II group ( $\mathrm{P} \leq 0.001)$ (fig.2C).

\subsubsection{Heart rate variability (HRV)}

Different domains of HRV were assessed including time domain SDNN, Frequency domain HF, and
Frequency domain LF/HF. As shown in figure 3, using One way ANOVA with Post-hoc Tukey test, DM II group showed significant deterioration of different HRV domains (time domain SDNN, Frequency domain HF, and Frequency domain $\mathrm{LF} / \mathrm{HF}$ ) compared to the $\mathrm{N}$ group both at 4 th and 8th weeks. However, these deteriorations in HRV of diabetic rats (group 3) were significantly improved with BDNF (group 4) and exercise (group 5) $(\mathrm{P}<0.05)$.

\subsubsection{Baroreflex sensitivity (BRS) test:}

As shown in figure 4, DM II group showed significant decrease in its BRS slope $(\mathrm{P} \leq 0.001)$ in comparison to $\mathrm{N}$ group at the $4^{\text {th }}$ week (after PE injection) and $8^{\text {th }}$ week (after PE AND GN injection). However, this decrease improved significantly in response to BDNF injection, and swimming in groups 4 and 5 respectively.
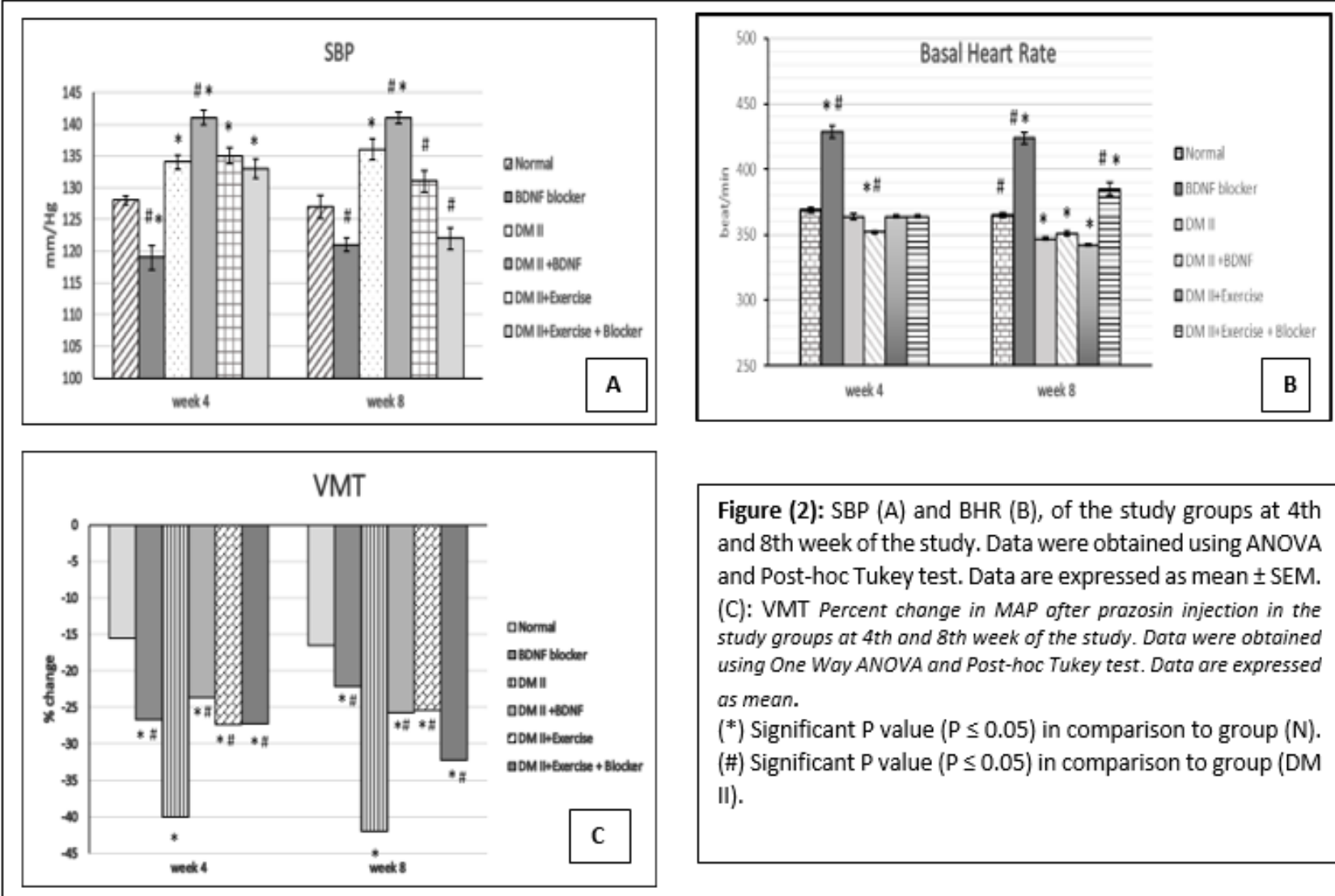

Figure (2): SBP (A) and BHR (B), of the study groups at 4th and 8th week of the study. Data were obtained using ANOVA and Post-hoc Tukey test. Data are expressed as mean \pm SEM. (C): VMT Percent change in MAP ofter prozosin injection in the study groups at 4 th and 8 th week of the study. Data were obtained using One Way ANOVA and Post-hoc Tukey test. Dato are expressed as mean.

$\left({ }^{*}\right)$ Significant $P$ value $(P \leq 0.05)$ in comparison to group $(N)$. (\#) Significant $P$ value $(P \leq 0.05)$ in comparison to group (DM II). 

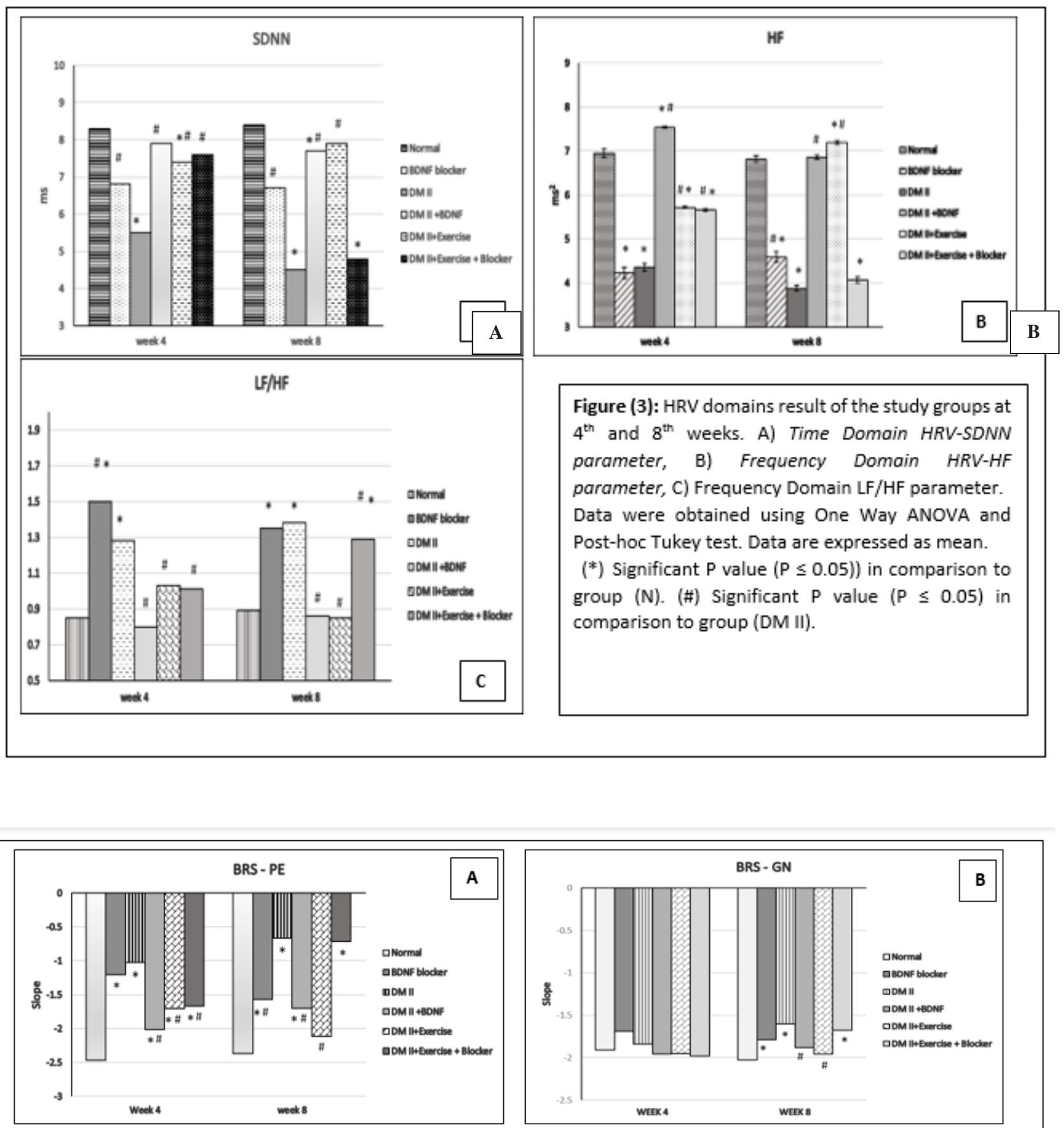

Figure (4): Slope of BRS after injection of A) PE, B) GN in the study groups at 4th and 8th week of the study. Data were obtained using One Way ANOVA and Post-hoc Tukey test. Data are expressed as means.

$\left(^{*}\right)$ Significant $P$ value $(P \leq 0.05)$ in comparison to group $(N)$.(\#) significant $P$ value $(P \leq 0.05)$ in comparison to group (DM II).

\subsection{Plasma BDNF levels:}

Induction of DM II in group 3 caused significant decrease in the plasma BDNF level in comparison to $\mathrm{N}$ group $(\mathbf{P} \leq \mathbf{0 . 0 0 1})$. however, $\mathrm{BDNF}$ injection, exercise, and BDNF blocker injection caused significant improvement of plasma
BDNF level of diabetic rats in groups $4,5 \& 6$ in comparison group 3 (fig.5). 


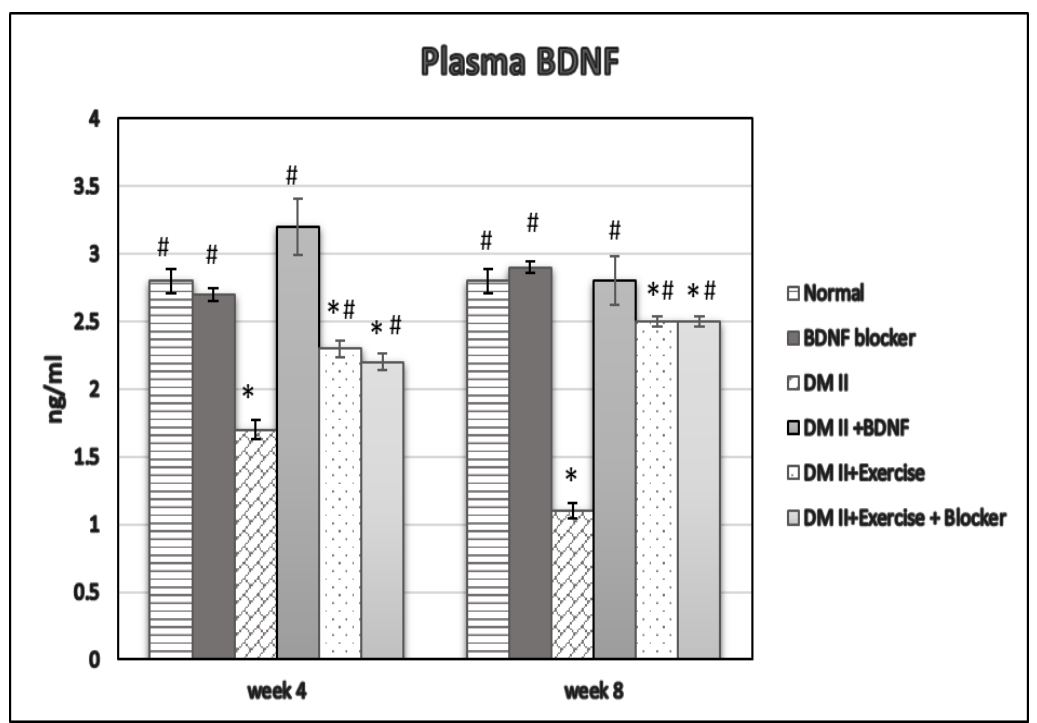

Fig.5: Plasma BDNF level in the study groups at 4th and 8th week. Data are expressed as mean and error bars represent SEM. Data were obtained using One Way ANOVA and Post-hoc Tukey test.

(*) Significant $\mathrm{P}$ value $(\mathrm{P} \leq 0.05)$ in comparison to group $(\mathrm{N})$.

(\#) significant $\mathrm{P}$ value $(\mathrm{P} \leq 0.05)$ in comparison to group (DM II).

\section{Discussion}

This study sought to investigate the role of BDNF in CAN caused by DM II in an animal model using Albino rats. Additionally, the aim was to assess the effects of swimming exercise on the same model and the mechanism by which swimming exercise may improve CAN and whether it's related to BDNF or not. In current study, the used STZ-NA DM II model prevented rats` body weight loss, severe hyperglycemia and caused insulin resistance not insulin deficiency suggested by the constant level of fasting plasma insulin throughout the study. These effects may be due to the protective effect of NA against STZ effects on beta cells. This opinion was supported by Tahara et al. (17) who compared body weight of STZ induced diabetic rats with STZ-NA induced diabetic rats and found that body weight significantly decreased to approximately $10 \%$ of that found in normal rats. However, they noticed that the STZ-induced body weight loss was depressed by nicotinamide in a dose-dependent manner. At the low dosage of 50 $\mathrm{mg} / \mathrm{kg}$, NA exerted only minor protection against the effect of STZ. On reaching the highest nicotinamide dosage of $200 \mathrm{mg} / \mathrm{kg}$, STZ-induced body weight loss was completely prevented (17). In the current study, NA dose of $180 \mathrm{mg} / \mathrm{kg}$ was used which prevented the decrease in rats` body weight. BDNF blocker injection significantly increased rats` body weight, RBG level and insulin level which made us pay attention to the possible mechanism by which BDNF may contribute in CAN and DM II as follows: insulin is an anabolic hormone which increases body weight. Since BDNF blocker increases insulin level so it led to a significant increase in rats` body weight and RBG level as this insulin can't facilitate the normal cellular uptake of glucose due to insulin resistance leading eventually to a compensatory hyperinsulinemia in a try from Beta cells to maintain normal blood glucose level. This means that BDNF blocker inactivated only Glucose Transporter 2,4 (GLUT 2,4) translocation while the other insulin-induced effects are still active and 
that most probably what happened in DM II when BDNF is decreased (18). Regarding heart rate, many researches have proved that STZ-induced diabetic models decrease the resting heart rate (19) (20) despite the resting tachycardia produced by CAN may be due to some sort of metabolic injury to the sinoatrial node in the heart. In this study, CAN and BDNF injection decreased heart rate in rats significantly compared to normal rats. Throughout the study, STZ-NA induced diabetes and BDNF injection significantly increased SBP in rats compared to normal. In contrast, swimming exercise significantly decreased SBP in diabetic rats at the 8th week of the study compared to their controls. Results showed that STZ-NA induced diabetes caused a significant deterioration in HRV values (decreased SDNN, LF \& HF and increased LF/HF ratio) which means parasympathetic deterioration and sympathetic overdominance that leads to CAN. BDNF injection in diabetic rats caused significant improvement in HRV parameters and ameliorated parasympathetic activity. These findings are consistent with Chang et al. (21) who showed that there is a positive correlation between plasma level of BDNF and HRV indices in healthy subjects Swimming exercise significantly improved HRV values in diabetic rats. These findings are consistent with Villafaina et al. (22) who made a systematic review and found that different types of physical exercise specially aerobic and strength exercises improved DM II patients and they concluded that the most important factor to improve HRV is that exercise programs with more than 3 days per week. In this study, STZ-NA induced diabetes caused a significant decrease in BRS slope compared to normal mostly due to autonomic dysfunction. These findings are in accordance with Sakamoto et al. (23). This work demonstrated that injection of BDNF and swimming exercise in diabetic rats significantly improved BRS slope compared to control. Regarding VMT results in the present work, Prazosin injection significantly decreased MAP greatly in STZ-NA induced diabetic group compared to both normal and diabetic exercising group. These findings are mostly due to the sympathetic over dominance in diabetic group and its great contribution in maintenance of baseline vascular resistance. When an alpha-adrenergic blocker as prazosin is administrated, the sympathetic activity is diminished leading to drop in MAP. Our results and explanation are consistent with Grise et al. (14). This, study revealed that plasma BDNF level in STZ-NA induced diabetic rats was significantly decreased compared to controls and improved by both BDNF injection and swimming exercise.

\section{Conclusion}

In conclusion, this study suggests that BDNF can be used as a treatment regimen for CAN as it can improve RBG, body weight, autonomic dysfunction and restore sympatho-vagal balance. Also swimming exercise has great therapeutic effect on CAN maybe by producing BDNF.

\section{Acknowledgment}

The authors acknowledge Technician of Physiology department of Suez Canal University for the significant contribution to the experimental part of the study.

Conflicts of Interest: The author declares no conflict of interest 
References

1. Vinik AI $\quad \& \quad$ Ziegler $\quad$ D: Diabetic Cardiovascular Autonomic Neuropathy, Circulation, 115(3), 2007.

2. Kuehl M \& Stevens MJ: Cardiovascular autonomic neuropathies as complications of diabetes mellitus, Nature Reviews Endocrinology, 8, 405, 2012.

3. Sornelli F, Fiore M, Chaldakov G \& Aloe L: Adipose tissue-derived nerve growth factor and brain-derived neurotrophic factor: Results from experimental stress and diabetes (Vol. 28 SpecNo, 2009.

4. Monteggia LM, Barrot M, Powell CM, Berton O, Galanis V, Gemelli T, Meuth S, Nagy A, Greene RW \& Nestler EJ: Essential role of brain-derived neurotrophic factor in adult hippocampal function, Proceedings of the National Academy of Sciences of the United States of America, 101(29), 1082710832, 2004.

5. Krabbe KS, Nielsen AR, Krogh-Madsen R, Plomgaard P, Rasmussen P, Erikstrup C, Fischer CP, Lindegaard B, Petersen AMW, Taudorf S, Secher NH, Pilegaard H, Bruunsgaard $\mathrm{H} \&$ Pedersen BK: Brainderived neurotrophic factor (BDNF) and type 2 diabetes, Diabetologia, 50(2), 431-438, 2007.

6. Mostarda C, Rogow A, Moraes Silva IC, De La Fuente RN, Jorge L, Rodrigues B, Heeren MV, Caldini EG, De Angelis K \& Irigoyen MC: Benefits of exercise training in diabetic rats persist after three weeks of detraining, Autonomic Neuroscience: Basic and Clinical, 145(1), 11-16, 2009.

7. Correia PR, Scorza FA, da Silva SG, Pansani A, Toscano-Silva M, de Almeida AC \& Arida RM: Increased basal plasma brain-derived neurotrophic factor levels in sprint runners, Neuroscience Bulletin, 27(5), 325, 2011.

8. Vaynman S, Ying $\mathbf{Z} \&$ Gomez-Pinilla $\mathbf{F}$ : Hippocampal BDNF mediates the efficacy of exercise on synaptic plasticity and cognition, European Journal of Neuroscience, 20(10), 2580-2590, 2004.

9. Lin YD, Hsu KL, Wu ET, Tsai MS, Wang CH, Chang CY \& Chang KC: Autonomic neuropathy precedes cardiovascular dysfunction in rats with diabetes, Eur J Clin Invest, 38(9), 607-614, 2008.

10. Koch MA: Chapter 18 - Experimental Modeling and Research Methodology A2 Suckow, Mark A. In S. H. Weisbroth \& C. L. Franklin (Eds.), The Laboratory Rat (Second Edition) (pp. 587-625). Burlington: Academic Press, 2006.

11. Jiménez-Maldonado A, de Álvarez-Buylla ER, Montero S, Melnikov V, CastroRodríguez E, Gamboa-Domínguez A, Rodríguez-Hernández A, Lemus $M$ \& Murguía JM: Chronic Exercise Increases Plasma Brain-Derived Neurotrophic Factor Levels, Pancreatic Islet Size, and Insulin Tolerance in a TrkB-Dependent Manner, PLOS ONE, 9(12), e115177, 2014.

12. Figard H, Mougin F, Gaume V \& Berthelot A: Combined intervention of dietary soybean proteins and swim training: effects on bone metabolism in ovariectomized rats, $\mathrm{J}$ Bone Miner Metab, 24(3), 206-212, 2006.

13. Oliveira TL, Candeia-Medeiros N, Cavalcante-Araújo PM, Melo IS, FávaroPípi E, Fátima LA, Rocha AA, Goulart LR, Machado UF, Campos RR \& Sabino-Silva R: SGLT1 activity in lung alveolar cells of diabetic rats modulates airway surface liquid glucose concentration and bacterial proliferation, Scientific Reports, 6, 21752, 2016. 
14. Grisé KN, Olver TD, McDonald MW, Dey A, Jiang M, Lacefield JC, Shoemaker JK, Noble EG \& Melling CWJ: High Intensity Aerobic Exercise Training Improves Deficits of Cardiovascular Autonomic Function in a Rat Model of Type 1 Diabetes Mellitus with Moderate Hyperglycemia, Journal of Diabetes Research, 8164518, 2016.

15. Chu CP, Cui BR, Kannan H \& Qiu DL: Alterations in the baroreceptor heart rate reflex in conscious inbred polydipsic (STR/N) mice, Physiol Res, 64(2), 173-182, 2015.

16. Béjot Y, Mossiat C, Giroud M, PrigentTessier A \& Marie C: Circulating and Brain BDNF Levels in Stroke Rats. Relevance to Clinical Studies, PLOS ONE, 6(12), e29405, 2011.

17. Tahara A, Matsuyama-Yokono A, Nakano

\section{R, Someya Y \& Shibasaki M:}

Hypoglycaemic Effects of Antidiabetic Drugs in Streptozotocin-Nicotinamide- Induced Mildly Diabetic and Streptozotocin-Induced Severely Diabetic Rats, Basic \& Clinical Pharmacology \& Toxicology, 103(6), 560$568,2008$.

18. Wilcox G: Insulin and insulin resistance, The Clinical biochemist. Reviews, 26(2), 19-39, 2005.
19. Malone JI, Cuthbertson DD, Malone MA \& Schocken DD: Cardio-protective effects of carnitine in streptozotocin-induced diabetic rats, Cardiovascular diabetology, 5(1), 2, 2006.

20. Becher PM, Lindner D, Frohlich M, Savvatis K, Westermann D \& Tschope C: Assessment of cardiac inflammation and remodeling during the development of streptozotocin-induced diabetic cardiomyopathy in vivo: a time course analysis, Int J Mol Med, 32(1), 158-164, 2013.

21. Chang WH, Lee IH, Chi MH, Lin SH, Chen KC, Chen PS, Chiu NT, Yao WJ \& Yang YK: Prefrontal cortex modulates the correlations between brain-derived neurotrophic factor level, serotonin, and the autonomic nervous system, Scientific Reports, 8(1), 2558, 2018

22. Villafaina S, Collado-Mateo D, Fuentes JP, Merellano-Navarro E \& Gusi N: Physical Exercise Improves Heart Rate Variability in Patients with Type 2 Diabetes: A Systematic Review, Curr Diab Rep, 17(11), 110, 2017.

23. Sakamoto M, Matsutani D \& Kayama Y: Clinical Implications of Baroreflex Sensitivity in Type 2 Diabetes, Int Heart J, 60(2), 241246, 2019. 